\title{
Systemic Infection by Pseudomonas aeruginosa in a Dog
}

\author{
Layze Cilmara Alves da Silva', Danielle Aluska do Nascimento Pessoa', Lisanka Ângelo Maia², Rodrigo \\ Antonio Torres Matos' \& Meire Maria da Silva Macêdo'
}

\begin{abstract}
Background: Pseudomonas aeruginosa is an important pathogen frequently associated with nosocomial infections affecting mainly immunosuppressed patients. In Veterinary Medicine, infections caused by $P$. aeruginosa are becoming increasingly frequent; infections are related to intrinsic or acquired resistance mechanisms, which limit the choice of effective agents. Case: This study describes the case of a four-month-old male Pitt Bull dog treated at the Small Animal Internal Medicine service of the Veterinary Hospital at the Health and Rural Technology Center of Federal University of Campina Grande, Patos/Paraíba. The patient presented with apathy, inappetence, moderate dehydration, tachypnea, tachycardia, hyperthermia, pale mucosae, small lesions in the pelvic limbs, with edema and subsequent widespread petechiae. Treatment with intravenous fluid therapy using $0.9 \% \mathrm{NaCl}$ with B-complex vitamins, and $20 \mathrm{mg} / \mathrm{kg}$ cephalexin every $12 \mathrm{~h}$ was established. The patient did not respond well to treatment, and died two days later. Necropsy was performed at the Veterinary Pathology sector of the Hospital and histopathological findings revealed focally extensive areas of necrosis associated to myriads of bacteria and mild mononuclear inflammatory infiltrates in the liver, heart and kidneys. Secretions and organ fragments were submitted to the Microbiology Laboratory of the same institution, which identified a systemic bacterial infection caused by $P$. aeruginosa. In vitro bacterial susceptibility to 15 different antimicrobials was assessed using the Bauer-Kirby disk diffusion test in Mueller Hinton agar. The agent exhibited multiple resistance to enrofloxacin, cephalexin, ceftiofur, gentamicin, imipenem, kanamycin, cephalothin, norfloxacin, amoxicillin, polymyxin B, ampicillin, tetracycline, and penicillin. It was sensitive to amikacin and neomycin only. Phenotypic detection was performed via disk approximation test (D-test) established by the Clinical and Laboratory Standard Institute (CLSI), which showed metallo-beta-lactamase (MBLs)-producing bacteria.

Discussion: Clinical-pathological and microbiological aspects confirmed a systemic infection by $P$. aeruginosa characterized by yellowish nodular lesions and occasional hemorrhage, associated with myriads of bacteria in the lumen of the vessels in multiple organs. The agent was probably disseminated hematogenously, and it is likely that the cutaneous lesions in the pelvic limbs were the entry point. Treatment using cephalexin proved to be inefficient for the animal of the present study, which may have been be due to the patient's immunosuppression and the agent's natural or acquired resistance to this drug; therefore, special care needs to be taken when using these antibiotics as a preventive measure against the dissemination of gram-negative (MBL)-producing P. aeruginosa. We can conclude that $P$. aeruginosa may cause systemic infection in dogs. Amikacin and neomycin are the most efficient antimicrobials for the in vitro elimination of the bacteria; however, other studies on the use of these drugs in vivo are needed. Considering the occurrence of resistance to multiple antimicrobials and the production of MBLs observed in this study, it is important to monitor $P$. aeruginosa through phenotypical and antimicrobial susceptibility tests to verify its level of resistance in diseases in Veterinary Medicine.
\end{abstract}

Keywords: microbiological, internal medicine, infections, Veterinary Medicine. 


\section{INTRODUCTION}

Pseudomonas aeruginosa is the most important strain of its species in Veterinary Medicine, although other species are also relevant in veterinary clinical practice, food hygiene, and water microbiology. Pseudomonas aeruginosa are aerobic and nonspore-forming bacteria, and present in the form of Gram-negative rods [6]. Infections caused by this agent are becoming increasingly frequent; they may occur acutely due to the production of toxins, and chronically owing to the formation of a thick biofilm. Infections can also occur with both forms, production of toxins and biofilms, which combined can cause septicemia [14]. In Veterinary Medicine, P. aeruginosa is observed in otitis, cystitis, endometritis, dermatitis, abscesses, and pneumonia in domestic animals [17].

Treatment of infections by Pseudomonas aeruginosa is complicated due to the antimicrobial resistance related to intrinsic and acquired mechanisms, limiting the choice of effective agents [5]. One of these mechanisms is the production of metallo-betalactamases (MBLs), which are enzymes responsible for the beta-lactam-resistant phenotype. The emergence of innumerous MBL-producing strains in various regions of the world requires the development of fast, practical, and low-cost tests to assist in the microbiological routine [10]. The purpose of this study is to report a case of systemic infection caused by $P$. aeruginosa in a dog, demonstrating clinical, pathological and microbiological characteristics of this infection.

\section{CASE}

A four-month-old male Pitt Bull dog was treated at the Small Animal Internal Medicine service of the Veterinary Hospital of the Health and Rural Technology Center at the Federal University of Campina Grande, Patos, Paraíba presented with muscle tremors, pain, and difficulty to walk. Clinical examination showed apathy, inappetence, moderate dehydration, tachypnea, tachycardia, hyperthermia, pale mucosae, and multiple petechiae throughout the body. The animal was hospitalized and received intravenous fluid therapy with $0.9 \% \mathrm{NaCl}$ with $\mathrm{B}$-complex vitamins, and $20 \mathrm{mg} / \mathrm{kg}$ cephalexin every $12 \mathrm{~h}$. The patient did not respond to treatment and died two days later. Necropsy showed a circular area of approximately $3 \mathrm{~cm}$ of diameter in the pelvic limb with an ulcerated center and elevated, irregular borders. Multifocal yellowish nodules varying from 0.2 to $1 \mathrm{~cm}$ of diameter were observed in the subcapsular surface of the kidneys, in the liver, left ventricular papillary muscles of the heart, and lungs. These nodules were surrounded by a reddish halo. Reddish areas were seen between the nodules, and also in the diaphragm, corticomedullary region of the kidneys, and in the serosa and mucosa of the bladder. The right pulmonary lobe was covered by a yellowish content.

Histopathological findings revealed focally extensive areas of necrosis associated with myriads of bacteria and mild mononuclear inflammatory infiltrate in the liver, heart and kidneys (Figure 1).

Organ fragments and secretions were submitted to the Microbiology Laboratory of the same institution, where the agent was identified. Bacterial growth of macroscopical, smooth, round colonies with a fluorescent greenish color and a characteristic sweet scent was observed in MacConkey agar; microscopical Gram-negative rods were also visualized. Biochemical tests classified the isolated colonies as catalase- and oxidase-positive, reducers of nitrate to nitrite, and nonsugar fermenting except for glucose; the agent was identified as P. aeruginosa (Figure 2 A) [12].

In vitro susceptibility was assessed in order to analyze the levels of bacterial resistance. The BauerKirby disk diffusion susceptibility test was used in Mueller Hinton agar to evaluate 15 different antimicrobials: amikacin, ampicillin, penicillin, amoxicillin, cephalexin, cephalothin, ceftiofur, gentamicin, neomycin, kanamycin, norfloxacin, enrofloxacin, polymyxin $\mathrm{B}$, imipenem and tetracycline. The agent exhibited multiple resistance to enrofloxacin, cephalexin, ceftiofur, gentamicin, imipenem, kanamycin, cephalotin, norfloxacin, amoxicillin, polimyxin B, ampicillin, tetracycline, and penicillin. It was sensitive to amikacin and neomycin only.

The disk approximation phenotypic test recommended by the Clinical and Laboratory Standard Institute (CLSI) was used to verify the production of MBL. A suspension of $P$. aeruginosa was diluted to reach the McFarland standard no. 0.5 and inoculated on the surface of a $4 \mathrm{~mm}$-high Mueller Hinton agar plate. Next, disks containing the antibiotics ceftazidime $(30 \mu \mathrm{g})$ and imipenem $(10 \mu \mathrm{g})$ were positioned in the plate next to a sterile disk of filter paper added with a chelating solution of EDTA (ethylenediaminetetraacetic acid). After a $20 \mathrm{~h}$ incubation period at $35^{\circ} \mathrm{C}$, the zone of 


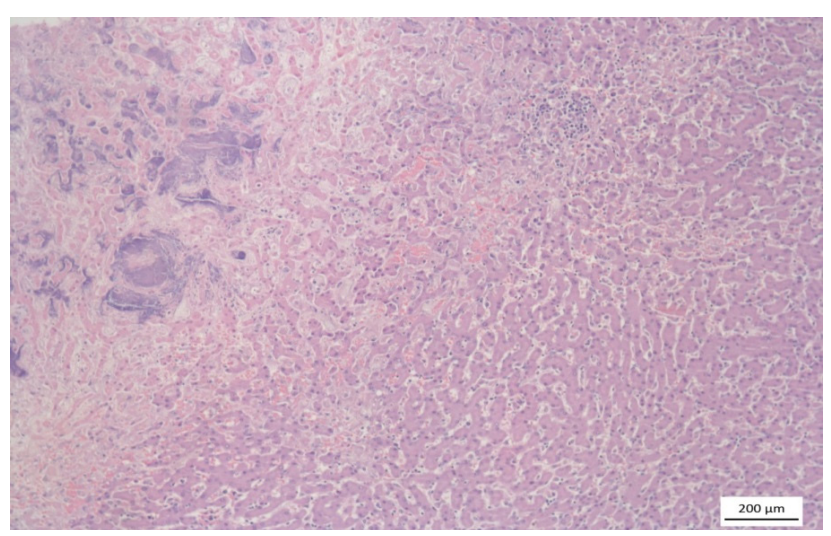

Figure 1. Liver. Focally extensive area of necrosis associated with myriads of intralesional and presence of adjacent mild mononuclear inflammatory [HE, obj 10x].

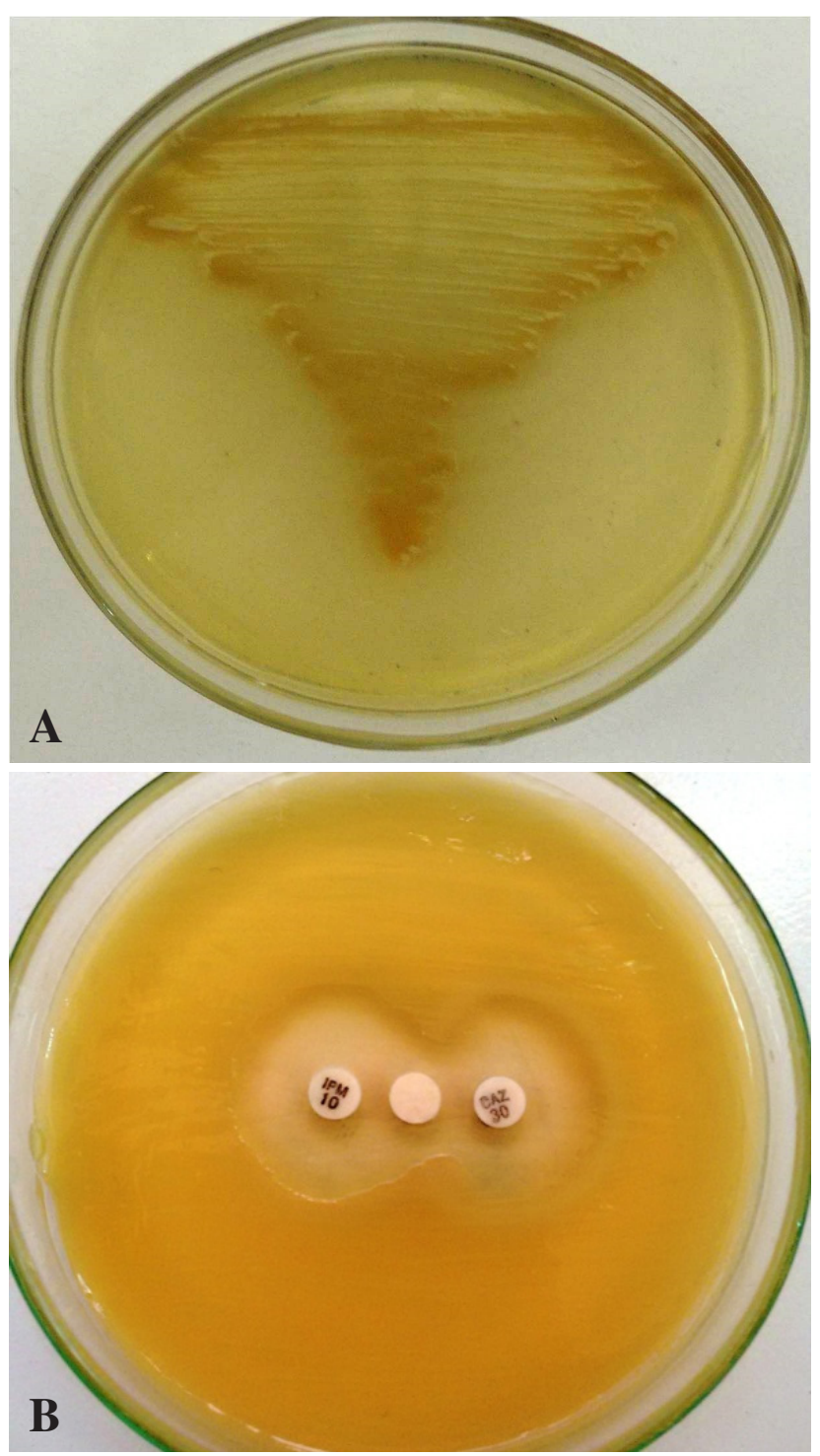

Figure 2. A- Humid, smooth, greenish colonies of Pseudomonas aeruginosa isolated from hepatic fragments in nutrient Agar. BPseudomonas aeruginosa presenting positive phenotypic test for metallo-beta-lactamase production. The test shows distortion and enhancement of the zone of inhibition of bacterial growth in the area where the chelating agent (EDTA) has been diffused. inhibition of bacterial growth in the agar diffused with EDTA was distorted and amplified, confirming the production of MBLs (Figure $2 \mathrm{~B}$ ).

\section{DISCUSSION}

Pseudomonas aeruginosa was diagnosed based on clinical and pathological aspects, and confirmed by microbiological tests. Systemic infection was characterized by yellowish nodular lesions and occasional hemorrhage, associated with myriads of bacteria in the lumen of vessels in multiple organs. The dissemination of the agent was possibly hematogenous; the cutaneous lesions in the pelvic limbs were probably the entry point for the systemic infection. P. aeruginosa is considered environmental; disseminated in waters, humid soils, and vegetable surfaces; it may occasionally cause infections in animals $[7,16]$.

The clinical signs observed may be unspecific; however, the presence of hyperthermia and disseminated petechiae are characteristic clinical presentations of septicemia, which are usually associated with the opportunistic behavior of the microorganism and decreased immunity of the animal $[11,16]$.

Cephalexin is a first generation cephalosporin, considered to be active against Gram-positive bacteria and some Gram-negative aerobic bacteria [4]. In the present study, cephalexin did not prove to be effective; great bacterial resistance was observed, and therefore cephalexin is not a drug of choice in the treatment of systemic infections caused by $P$. aeruginosa. Similar results were found in a study of 18 samples of Pseudomonas aeruginosa, which presented elevated rates of resistance to cephalexin (99\%) and cefotaxime (75.6\%) in the in vitro susceptibility test [13]. The fact that the animal did not respond well to treatment with this antibiotic may be related to immunosuppression and natural or acquired resistance to these drugs by the infectious agent [16], which makes the clinical condition of the patient more severe and difficult to reverse [15]. Thereby, caution is recommended when using these antibiotics as a preventive measure against the dissemination of Gram-negative bacteria such as MBL-producing $P$. aeruginosa. In terms of antibiotic sensitivity, the most effective in vitro antimicrobials were amikacin and neomycin, in agreement with results obtained in other studies [3].

The multiple resistance rate observed in this case confirms observations of previous studies, which 
indicate a progressive, gradual increase of antibiotic resistance in Veterinary Medicine in the past decades, complicating the control of several conditions [9].It is important to be aware of infections caused by MBLproducing bacteria to motivate the preventive measures required. In Veterinary Medicine the studies about MBLs are still limited; however, in Human Medicine, MBLs play a crucial role in the antibiotic resistance mechanisms $[1,2,8,18,10]$.

Therefore, we can conclude that $P$. aeruginosa can cause systemic infection in dogs. The antimicrobials proven effective to eliminate the bacteria in vitro were amikacin and neomycin. However, in vivo studies about the use of these drugs are required.

The agent must be identified by means of a microbiological culture followed by a bacterial susceptibility test before treatment is instituted.

Due to the elevated multiple-resistance and production of MBLs, it is important to monitor P. aeruginosa through phenotypical tests to verify its level of resistance in the various conditions affecting animals.

Declaration of interest. The authors report no conflicts of interest. The authors alone are responsible for the content and writing of the paper.

\section{REFERENCES}

1 Arakawa Y., Shibata N., Shibayama K., Kurokawa H., Yagi T., Fujiwara H. \& Goto M. 2000. Convenient test for screening metallo B-lactamase: producing Gram-negative bacteria by using thiol compounds. Journal of Clinical Microbiology. 38: 40-43.

2 Bush K. 2001. New E-lactamases in Gram-negative bacteria: diversity and impact on the selection of antimicrobial therapy. Clinical Infectious Diseases. 32(7): 1085.

3 Figueiredo E.A.P., Ramos H., Maciel M.A.V., Vilar M.C.M., Loureiro N.G. \& Pereira R.G. 2007. Pseudomonas aeruginosa: Freqüência de Resistência a Múltiplos Fármacos e Resistência Cruzada entre Antimicrobianos no Recife/ PE. Revista Brasileira de Terapia Intensiva. 19 (4): 421-427.

4 Greene C.E. \& Watson D.J. 2006. Antibacterial chemotherapy. In: Greene C.E. (Ed). Infectious diseases of the dog and cat. 3rd edn. Saint Louis: Saunders-Elsevier, pp. 274-301.

5 Hancock R.E. 1998. Resistence mechanisms in Pseudomonas aeruginosa and other non fermentative gram-negative bacteria. Clinical Infectious Diseases. 27(1): 93-99.

6 Hirsh D.C. \& Zee Y.C. 2003. Microbiologia Veterinária. Rio de Janeiro: Guanabara Koogan, 446p.

7 Kiska D.L. \& Gilligan P.H. 1999. Pseudomonas. In: Murray P.R., Baron E.J., Pfaller M.A., Tenover F.C. \& Yolken R.H. (Eds). Manual of Clinical Microbiology. 7th edn. Washington DC: ASM Press, pp.517-525.

8 Lee K., Chong Y., Shin H.B., Kim Y.A., Yong D. \& Yum J.H. 2001. Modified Hodge and EDTA-disk synergy tests to screen metallo- $\beta$-lactamase-producing strains of Pseudomonas and Acinetobacter species. Clinical Microbiology and Infection. 7(2): 88-102.

9 Mateu E. \& Martin M. 2001. Why is anti-microbial resistance a veterinary problem as well? Journal of Veterinary Medicine: Series B. 48(8): 569- 581.

10 Mendes R.E., Castanheira M., Pignatari A.C.C. \& Gales A.C. 2006. Metalo- $\beta$-lactamases. Journal Brazilian Patology and Laboratory Medicine. 42(2): 103-113.

11 Murray P.R. 2006. Microbiología Médica. 5.ed. Rio de Janeiro: Elsevier Science, 979p.

12 Murray P.R., Baron E.J., Pfaller M.A., Tenover F.C. \& Yolken R.H. 1995. Manual of Clinical Microbiology. 6th edn. Washington D.C.: ASM Press, 1482p.

13 Oliveira L.C., Medeiros C.M.O., Silva I.N.G., Monteiro A.J., Leite C.A.L. \& Carvalho C.B.M. 2005. Susceptibilidade a antimicrobianos de bactérias isoladas de otite externa em cães. Arquivo Brasileiro de Medicina Veterinária e Zootecnia. 57(3): 405-408.

14 Palleroni N.J. 1998. Introduction to the aerobic pseudomonads. In: Collier L., Balows A. \& Sussman M. (Eds). Topley \& Wilson's Microbiology and microbial infections - Systematic bacteriology. 9th edn. London: Arnold Publishers, pp.1091-1108.

15 Poeta P. \& Rodrigues J. 2008. Detecção da resistência a antibióticos de bactérias isoladas de casos clínicos ocorridos em animais de companhia. Arquivo Brasileiro de Medicina Veterinária e Zootecnia. 60(2): 506-508.

16Quinn P.J. Carter M.E., Markey B. \& Carter G.R. 1999. Clinical Veterinary Microbiology. Edinburgh: Mosby Harcourt Publishers Ltd., 648p. 
L.C.A. Silva, D.A.N. Pessoa, L.A. Maia, R.A.T. Matos \& M.M.S. Macêdo. 2016. Systemic Infection by Pseudomonas aeruginosa in a Dog. Acta Scientiae Veterinariae. 44(Suppl 1): 164.

17 Radostits O.M., Blood D.C. \& Gay C.C. 2000. Veterinary Medicine - A textbook of the diseases of cattle, sheep, pigs, goats and horses. 8th edn. Philadelphia: Baillière Tindall, pp. 881-884.

18 Walsh T.R., Toleman M.A., Poirel L. \& Nordmann P. 2005. Metallo- $\beta$-Lactamases: The Quiet before the Storm? Clinical Microbiology Reviews. 18(2): 306-325. 